\title{
INFLUENCE OF AGE OF EWE AND PHOTOPERIOD ON THE INTERVALS BETWEEN PARTURITION AND FIRST OESTRUS IN LACTATING AND NON- LACTATING EWES AT DIFFERENT NUTRITIONAL LEVELS
}

\author{
G. L. HUNTER* AND I. M. R. VAN AARDE \\ Department of Agricultural Technical Services, \\ Stellenbosch, South Africa
}

(Received 4th February 1974)

\begin{abstract}
Summary. A total of 131 2- to 6-year-old Mutton Merino ewes in two experiments were maintained in pens during the post-partum period and were exposed either to an artificial photoperiod of decreasing daylength, or to the naturally increasing photoperiod. After lambing in July, the ewes either were deprived of their lambs or they reared one lamb for 40 days. In both groups, the ewes were fed at one of four nutritional levels until the first post-partum oestrus had been recorded. The proportion of ewes showing first oestrus within 90 days of lambing was $44 \%$ for those subjected to the artificial photoperiod compared with $67 \%$ for those exposed to the natural photoperiod. First oestrus in the ewes which showed first oestrus more than 90 days after lambing was less delayed in those exposed to the artificial photoperiod. Nutritional level had no effect on the time of resumption of oestrus. In the natural photoperiod, $67 \%$ of lactating ewes and $68 \%$ of non-lactating ewes showed oestrus in 56.3 and 42.1 days, respectively, and a similar effect was observed in those exposed to the artificial photoperiod. In the natural photoperiod, $33 \%$ of 2-year-old, $53 \%$ of 3-year-old and $84 \%$ of mature ewes showed first oestrus within 90 days of lambing. It was concluded that, in most periods of the year, many ewes of this breed can be remated within 2 to 3 months of lambing and may thus be able to lamb three times in 2 years.
\end{abstract}

\section{INTRODUCTION}

In a previous experiment, the interval to oestrus after parturition in young (2-year-old) Mutton Merino ewes was found to depend primarily on the lambing date (Hunter \& Van Aarde, 1973). When lambing occurred during the breeding season (March/April), most ewes came into oestrus about 6 to 8 weeks after lambing. If lambing took place around the start of the breeding

* Present address: P.O. Box 3028, Stellenbosch, South Africa. 
season (November), the ewes were anoestrous for 8 to 10 weeks. After lambing in July, however, about a month after the winter solstice when the breeding season is usually regarded as waning, the interval to first oestrus varied from 4 to 28 weeks, with a mean of 14 to 15 weeks. It was also observed that the resumption of sexual activity did not differ in ewes which suckled lambs for 1 or for 40 days. In addition, following lambing in July but not at other times, the interval to first ovulation post partum was reduced by feeding the ewes after lambing on a higher nutritional plane. In no season, however, did feeding level influence the interval to oestrus.

It appeared, therefore, that the end of the breeding season was the least favourable lambing time for early resumption of oestrous activity and that a better understanding of the post-partum period at this time of year in particular might help to achieve an increase in lambing frequency. The length of the post-partum anoestrus in ewes lambing in July was re-examined, therefore, to determine the effects of variation in the age of ewe, the photoperiod, the length of the suckling period, and the feeding level after parturition.

\section{MATERIALS AND METHODS}

In Exp. 1, eighty-six Mutton Merino ewes, ranging in age from 2 to 6 years, were maintained in partly roofed, open-sided pens and, at lambing, were allotted to groups at random in a $2 \times 4$-factorial design. Within $24 \mathrm{hr}$ of birth, the lambs were removed from the ewes in half the groups; the remaining ewes suckled one lamb until weaning at 40 days of age. Four different feeding levels were applied during the period after lambing until each ewe had shown oestrus; the levels were $70 \%, 100 \%, 130 \%$ and $160 \%$ of the estimated energy requirements for maintenance, or $0.0184,0.0253,0.0328$ and $0.0402 \mathrm{~kg}$ total digestible nutrients (TDN) per day per unit metabolic size $\left(\right.$ Weight $^{0.75}$ ). Lactating ewes received an additional daily allowance of $0.65 \mathrm{~kg}$ TDN during the 40-day suckling period. The ewes were group-fed, and the daily feed allowance of each ewe from lambing until the first oestrus after parturition was determined following weighing within $24 \mathrm{hr}$ after lambing. As each ewe lambed and was allocated to a treatment group, or was removed from a group at the end of lactation or after she had shown oestrus, her allowance was added to or subtracted from the daily ration for the group.

Experiment 2 was conducted simultaneously and included eighty-nine ewes from the same source and of a similar age range as those in Exp. 1. (As will be explained, forty-four ewes were common to both experiments.) Experiment 2 was designed as a $2^{3}$-factorial, with lactating and non-lactating ewes and two feeding levels $(100 \%$ and $160 \%$ of maintenance requirements) exactly as in Exp. 1. The third factor in Exp. 2 was the application of an artificial photoperiod versus the natural photoperiod, the former being designed to simulate the autumnal pattern of the natural photoperiod during the latter part of pregnancy and during the post-partum period, i.e. a reduction of 'daylength' by a total of $15 \mathrm{~min}$ per week (see Text-fig. 1). This was achieved in the pens (which were similar to those used in Exp. 1) by the provision of lights during appropriate periods after sunset and before sunrise. Artificial 
lighting for each $110 \mathrm{ft}^{2}\left(10.2 \mathrm{~m}^{2}\right)$ of pen space consisted of two 8-ft $(2.44 \mathrm{~m})$ long, $75 \mathrm{~W}$ 'daylight' fluorescent lamps (Philips S96T12/55) and one $150 \mathrm{~W}$ incandescent lamp, placed $6 \mathrm{ft}(1.83 \mathrm{~m})$ above the floor.

The ewes which were common to both experiments were those in Exp. 1 that were subjected to a natural photoperiod in the four treatment groups at the $100 \%$ and $160 \%$ feeding levels. These ewes also served as controls for the forty-five ewes (four groups) subjected to an artificial photoperiod in Exp. 2.

The first oestrus after lambing was determined for the ewes in both experiments by observing the raddle marks which resulted from matings by the vasectomized rams kept with each group, the occasional anovulatory oestrus which occurred within 2 to 3 days of lambing being ignored. All ewes were weighed again 40 days after lambing.

\section{RESULTS}

The liveweight changes of the ewes during the first 40 days after lambing are summarized in Table 1 . Weight changes did not vary with the age of the ewe, but were consistently smaller in the lactating ewes than in the non-lactating ewes. This suggests that the additional allowance of feed during the suckling period, which was intended to counter the nutritional drain of lactation, was excessive on the two lower feeding levels in comparison with its effect on the two higher levels. Apart from this, the attempt to vary the nutritional status of the ewes on the different feeding treatments by altering the basic feeding levels, was apparently achieved.

Table 1. Mean changes in body weight of ewes during the first 40 days after lambing

\begin{tabular}{|c|c|c|c|c|c|c|c|c|c|}
\hline \multirow[b]{3}{*}{ Ewes } & \multicolumn{8}{|c|}{ Feeding level } & \multirow[b]{3}{*}{ Photoperiod } \\
\hline & \multicolumn{2}{|c|}{$70 \%$} & \multicolumn{2}{|c|}{$100 \%$} & \multicolumn{2}{|c|}{$130 \%$} & \multicolumn{2}{|c|}{$160 \%$} & \\
\hline & $\mathcal{N}$ & $\begin{array}{c}\text { Wt } \\
\text { change } \\
(\mathrm{kg})\end{array}$ & $\mathcal{N}$ & $\begin{array}{c}\text { Wt } \\
\text { change } \\
(k g)\end{array}$ & $\mathcal{N}$ & $\begin{array}{c}\text { Wt } \\
\text { change } \\
(k g)\end{array}$ & $\mathcal{N}$ & $\begin{array}{c}\text { Wt } \\
\text { change } \\
(\mathrm{kg})\end{array}$ & \\
\hline $\begin{array}{l}\text { Lactating } \\
\text { Non-lactating }\end{array}$ & $\begin{array}{l}10 \\
11\end{array}$ & $\begin{array}{l}-1 \cdot 1 \\
-5 \cdot 5\end{array}$ & $\begin{array}{l}10 \\
11\end{array}$ & $\begin{array}{l}-0.4 \\
-2.5\end{array}$ & $\begin{array}{l}10 \\
11\end{array}$ & $\begin{array}{l}+0.9 \\
+1.4\end{array}$ & $\begin{array}{l}12 \\
11\end{array}$ & $\begin{array}{l}+2 \cdot 8 \\
+3 \cdot 6\end{array}$ & Natural \\
\hline $\begin{array}{l}\text { Lactating } \\
\text { Non-lactating }\end{array}$ & & & $\begin{array}{l}12 \\
11\end{array}$ & $\begin{array}{l}-1.6 \\
-3.7\end{array}$ & & & $\begin{array}{l}11 \\
11\end{array}$ & $\begin{array}{l}+1 \cdot 0 \\
+2 \cdot 9\end{array}$ & Artificial \\
\hline
\end{tabular}

For groups of 10,11 and 12 ewes $(\mathrm{N})$, standard errors of means were $1.13,1.08$ and 1.03 respectively.

The distributions of the first oestrus after parturition in the ewes in both experiments are illustrated in Text-fig. 1. The most striking feature of the observations on ewes exposed to the natural photoperiod was the existence of two separate populations within each of the eight treatment groups. The data can be shown to be consonant with a model comprised of two components of normal response by partitioning the ewes in each of the eight samples into those showing oestrus within 90 days of lambing ('early' oestrus) and those in which recommencement of sexual activity was delayed until the next breeding season ('late' oestrus). When the unpartitioned samples were analysed by means 


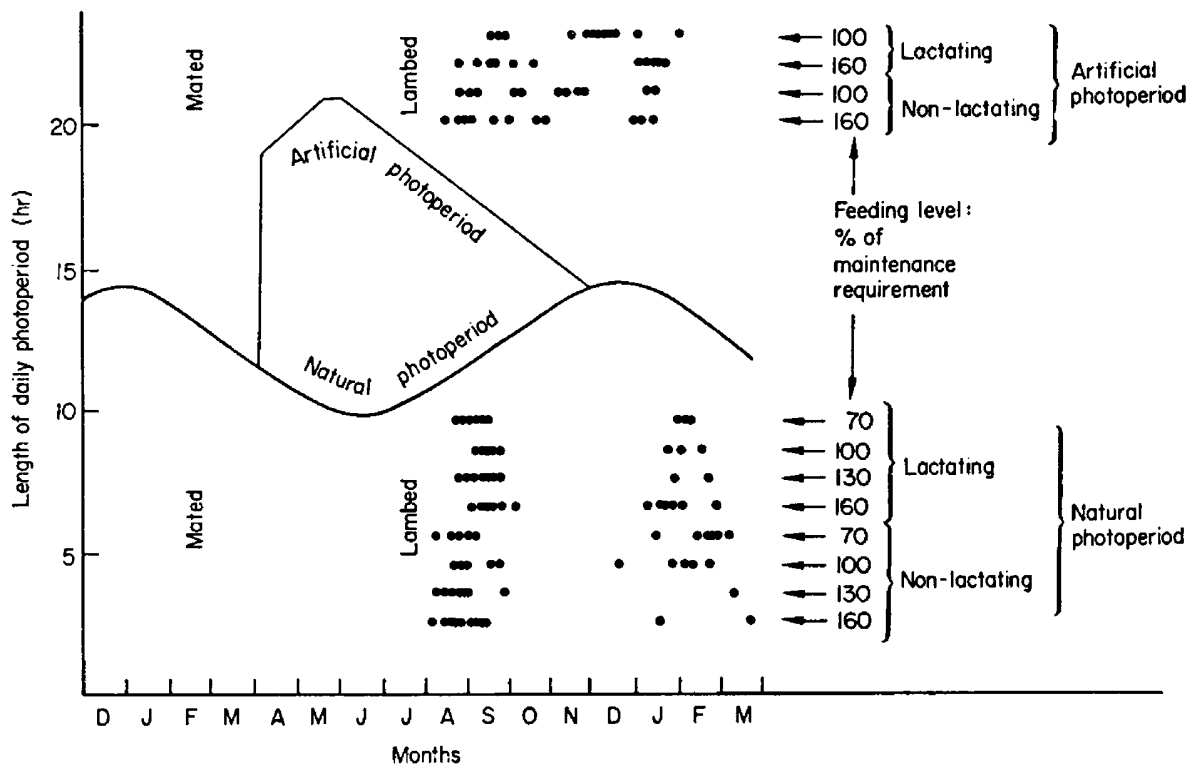

TExT-FIG. 1. Mating, lambing and first post-partum oestrus in Mutton Merino ewes in relation to the time of year and the length of the respective daily photoperiods. Each observation of oestrus is represented by a dot opposite the appropriate treatment listed on the right.

of the Shapiro-Wilk test for a single normal component (Shapiro \& Wilk, 1965), the probability of significance of the test statistic was less than 0.01 in each of the eight cases. Partitioning yielded thirteen samples of sufficient size for reanalysis by the same test and evidence of heterogeneity was found only for early oestrus among non-lactating ewes on the $130 \%$ nutritional level. This was evidently due to a single outlying value contributed by a 2 -year-old ewe.

On the strength of these analyses, the data obtained for early and late oestrus on the natural photoperiod were analysed separately by means of analysis of variance of unweighted means (Snedecor, 1964). Among the samples of early oestrus (Table 2), the only differences found could be attributed to lactating ewes showing first oestrus some 15 days later than non-lactating

Table 2. The interval from lambing to first oestrus for lactating and non-lactating ewes exposed to natural photoperiod and various nutritional levels

\begin{tabular}{|c|c|c|c|c|c|c|c|c|}
\hline \multirow{2}{*}{$\begin{array}{l}\text { Ewes showing: } \\
\text { Feeding level: }\end{array}$} & \multicolumn{4}{|c|}{ Early oestrus } & \multicolumn{4}{|c|}{ Late oestrus } \\
\hline & $70 \%$ & $100 \%$ & $130 \%$ & $160 \%$ & $70 \%$ & $100 \%$ & $130 \%$ & $160 \%$ \\
\hline $\begin{array}{l}\text { Lactating } \\
\text { Mean interval } \\
\text { (days) } \\
\text { No. of ewes }\end{array}$ & $\begin{array}{r}52 \\
7\end{array}$ & $\begin{array}{r}59 \\
7\end{array}$ & $\begin{array}{r}54 \\
8\end{array}$ & $\begin{array}{r}61 \\
6\end{array}$ & $\begin{array}{r}195 \\
3\end{array}$ & $\begin{array}{r}198 \\
3\end{array}$ & $\begin{array}{r}208 \\
2\end{array}$ & $\begin{array}{r}188 \\
6\end{array}$ \\
\hline $\begin{array}{l}\text { Non-lactating } \\
\text { Mean interval } \\
\text { (days) } \\
\text { No. of ewes }\end{array}$ & $\begin{array}{r}37 \\
5\end{array}$ & $\begin{array}{r}48 \\
6\end{array}$ & $\begin{array}{l}38 \\
10\end{array}$ & $\begin{array}{r}43 \\
9\end{array}$ & $\begin{array}{r}214 \\
6\end{array}$ & $\begin{array}{r}191 \\
5\end{array}$ & $\begin{array}{r}238 \\
1\end{array}$ & $\begin{array}{r}214 \\
2\end{array}$ \\
\hline
\end{tabular}


ewes ( 41.2 days versus 56.3 days; $P<0.01)$; differences due to feeding level were not significant $(P>0 \cdot 25)$. Furthermore, there were no differences between lactating and non-lactating ewes in the numbers which showed early oestrus $(67 \%$ and $68 \%$, respectively). Among the ewes showing late oestrus, no differences were found $(P$ about $0 \cdot 15)$. In such ewes, however, the periods between lambing and first oestrus varied around their means with a standard deviation of 20 days, as opposed to one of only 11 days for ewes showing early oestrus $(P<0 \cdot 01)$.

The recommencement of sexual activity was delayed until the next breeding season less frequently in mature ewes than in younger ewes (Table 3). This further source of heterogeneity was confirmed by analysis of variance after angular transformation, taking account of the different numbers of ewes in each group (Rao, 1952). The components of $\chi^{2}$ due to lactational status, age (eliminating lactational status) and interaction were $0.11(P=0.75$, d.f. $=1)$, $18.39(P<0.01$, d.f. $=2)$ and $0.10(P=0.95$, d.f. $=2)$, respectively. This clearly established that the percentage of ewes showing early oestrus increased with the maturity of the ewes and was not affected by lactational status.

Table 3. Percentages of lactating and non-lactating ewes of different ages and exposed to the natural photoperiod showing first oestrus within 90 days of lambing

\begin{tabular}{l|ccc}
\hline & \multicolumn{3}{|c}{ Age of ewes } \\
& 2 years & 3 years & Mature \\
\hline Lactating & $36(4 / 11)$ & $57(4 / 7)$ & $85(22 / 26)$ \\
Non-lactating & $29(2 / 7)$ & $50(5 / 10)$ & $84(21 / 25)$ \\
Over-all & $33(6 / 18)$ & $53(9 / 17)$ & $84(43 / 51)$ \\
\hline
\end{tabular}

Number of ewes shown in parentheses.

The data obtained from ewes exposed to the artificial photoperiod gave no indication of nutritional effects (Text-fig. 1) and, in view of the absence of such effects on the ewes exposed to the natural photoperiod, this factor was disregarded in further analyses. In order to test for the presence in the samples of more than one component due to breeding season (possibly related to the age of the ewe) as in the results for the natural photoperiod, the data were classified into six samples according to age and lactational status, of which four were of sufficient size for analysis by the Shapiro-Wilk test. The significance levels of the four test statistics were combined by Fisher's method (Snedecor, 1964), resulting in a $P$ value of 0.20 . This indicated that the chosen classification yielded homogeneous samples and also supported the assumption concerning the absence of nutritional effects. The data (summarized in Table 4) could thus be analysed by applying the usual analysis of variance for unequal sub-class numbers. No significant differences due to age $(P=0.22$, d.f. $=2$ and 39) or interaction $(P=0.80$, d.f. $=2$ and 39$)$ were found, but the numbers of young ewes were small. On the other hand, lactation seemed to have delayed the resumption of sexual activity $(P=0.075$, d.f. $=1$ and 39$)$. The least 
squares estimate of the delay (adjusted for possible age effects) was 15 days, which agreed with the value obtained for ewes coming into oestrus early in the natural photoperiod. The present estimate was, however, much less precise, the standard error of estimate being 8 days, compared with 3 days for ewes showing early oestrus in the natural photoperiod. The low precision of the present estimate was due to the large variation within the ewes subjected to artificial light; the standard deviation within groups was 51 days, which was much larger than those given previously for the ewes exposed to the natural photoperiod after they had been separated into those showing early and those showing late oestrus.

Table 4. The interval from lambing to first oestrus for lactating and non-lactating ewes of different ages and exposed to the artificial photoperiod

\begin{tabular}{l|rcc}
\hline & \multicolumn{3}{|c}{ Age of ewes } \\
& 2 years & years & Mature \\
\hline $\begin{array}{l}\text { Lactating } \\
\quad \text { Mean interval (days) }\end{array}$ & 182 & 98 & 117 \\
$\quad$ No. of ewes & 2 & 2 & 19 \\
$\begin{array}{l}\text { Non-lactating } \\
\text { Mean interval (days) }\end{array}$ & 115 & 98 & 89 \\
$\quad$ No. of ewes & 6 & 6 & 10 \\
\hline
\end{tabular}

\section{DISCUSSION}

The differences in the timing of the first post-partum oestrus between the ewes lambing in July in the experiment previously reported (Hunter \& Van Aarde, 1973) and those exposed to the natural photoperiod in the present experiment are accounted for, to a large extent, by the fact that at the start of the former experiment the ewes were all 2-year-olds, whereas in the present experiment only $21 \%$ were 2 -year-olds and the rest were older ewes. Among the comparable 2 -year-old ewes, $24 \%$ in the previous experiment and $33 \%$ in the present experiment showed their first post-partum oestrus by the end of October, compared with $53 \%$ of 3-year-old ewes and $84 \%$ of mature $(>3$ year-old) ewes in the present experiment exposed to the natural photoperiod. These results indicate that most mature ewes of this breed are capable of an early return to oestrus after lambing in July, but that the young ewes are less likely to show an early return. On the other hand, the young ewes in the previous experiment, which lambed in July and did not show oestrus by the end of October, experienced it without delay thereafter and most had done so by the end of January. Consequently, there was no evidence in those data for the existence of two separate populations due to a proportion of the ewes delaying resumption of sexual activity until the next breeding season. In contrast to this, in the present experiment, ewes that were kept in the natural photoperiod and did not show oestrus within 90 days of lambing, did not return to oestrus until well into the next breeding season-January was only the beginning of 
overt sexual activity for them. This may, perhaps, be explained by the fact that the ewes in the present experiment were generally in poorer condition at lambing than were those in the earlier trial. The condition of ewes at lambing may be a more important factor in determining the post-partum sexual activity of the ewe than the feeding level after lambing. The present experiments have refuted our earlier hypothesis that feeding level after lambing may influence the interval to oestrus post partum.

The proportion of ewes showing first oestrus within 90 days of lambing was $44 \%$ for those subjected to an artificial photoperiod compared with $67 \%$ for those exposed to the natural photoperiod. Although the artificial photoperiod clearly altered the pattern of oestrus, the relatively high standard deviation of these data (51 days) indicates a rather variable influence on the return to oestrus. The apparent 'sense of urgency' to resume oestrus before the end of the breeding season, after lambing in July when exposed to the natural photoperiod (the standard deviation of the early heats was only 11 days) seems to have been moderated by the artificial photoperiod. The artificial photoperiod appeared to hasten considerably, however, the resumption of sexual activity in the ewes not in oestrus within 90 days of lambing.

The use of artificial light to reduce the interval between lambing and remating is of interest in certain intensive systems of lamb production (Goot, 1969; Ducker \& Bowman, 1972; Orskov \& Robinson, 1972). Very little is known at present about the rôle of the photoperiod in breeds such as the Mutton Merino, which have long breeding seasons and which commonly recommence oestrous activity before the summer solstice. Nevertheless, a number of South African breeds with such extended breeding seasons show, during the period of decreasing daylength, both maximum oestrous activity and also maximum ovulation rate. This suggests that the ewes have retained some sensitivity to the same change in photoperiod as that which stimulates activity in breeds with restricted breeding seasons. The use of the artificial photoperiod in the present experiment has confirmed that the animals were sensitive to such an effect, but no particular advantage in its use has been demonstrated. In fact, the observations that have been made in this project (see also Hunter \& Van Aarde, 1973) suggest strongly that substantial numbers of ewes of breeds such as the Mutton Merino, are, following lambing at most periods of the year, likely to be able both to lactate for 6 weeks and to mate again within 2 to 3 months. Assuming conception rates at such matings are adequate, the ewes should be able to lamb three times in 2 years without it being necessary to use artificial stimuli of any kind. This lambing frequency requires to be put to the test under practical conditions and effective systems of management devised.

\section{AGKNOWLEDGMENTS}

This project was financed by the South African Department of Agricultural Technical Services. Thanks are due to the staff of the Welgevallen Experiment Station for care of the experimental animals, to Dr L. P. Vosloo for advice, and to $\mathrm{Mr} \mathrm{J}$. H. Randall for assistance with computations. 


\section{REFERENCES}

Ducker, M. J. \& Bowman, J. C. (1972) Photoperiodism in the ewe. 5. An attempt to induce sheep of three breeds to lamb every eight months by artificial daylength changes in a non-light-proofed building. Anim. Prod. 14, 323-334.

Goot, H. (1969) Effect of light on spring breeding of Mutton Merino ewes. F. agric. Sci., Camb. 73, $177-180$.

HunTer, G. L. \& VAN AARDE, I. M. R. (1973) Influence of season of lambing on post-partum intervals to ovulation and oestrus in lactating and dry ewes at different nutritional levels. F. Reprod. Fert. $32,1-8$.

Ørskov, E. R. \& Robinson, J. J. (1972) Recent advances in ewe and lamb nutrition. Rep. Rowett Res. Inst. 28, 116-129.

RAo, C. R. (1952) Advanced Statistical Methods in Biometric Research. Wiley, New York.

ShapIRo, S. S. \& WILK, M. B. (1965) An analysis of variance test for normality (complete samples). Biometrika, 52, 591-611.

Snedecor, G. W. (1964) Statistical Methods, 5th edn. Iowa State University Press, Ames. 